\title{
CONTROLE JUDICIAL DO ORÇAMENTO PÚBLICO: INSTRUMENTO PARA EFETIVAÇÃO DE POLÍTICAS PÚBLICAS NA EDUÇAÇÃO
}

\section{JUDICIAL CONTROL OF THE PUBLIC BUDGET: INSTRUMENT FOR IMPLEMENTING PUBLIC POLICIES IN EDUCATION}

\author{
JAIME DOMINGUES BRITO ${ }^{1}$
}

WILLIAN ALVES DE SOUZA ${ }^{2}$

\begin{abstract}
RESUMO: Este trabalho tem o objetivo de demonstrar a legitimidade da intervenção judicial nas políticas públicas ligadas ao direito à educação, contrapondo o argumento de violação ao Princípio da Separação dos Poderes, à discricionariedade administrativa e à reserva do possível. Aborda o direito à educação como um direito fundamental, bem como a necessidade da previsão de políticas públicas educacionais nas peças orçamentárias. Trata da judicialização da política pública e a possibilidade de controle do orçamento público. Utiliza, como fundamentação teórica, análise de textos normativos, doutrinários e entendimentos firmados pelos Tribunais pátrios. Emprega procedimento técnico de pesquisa bibliográfica, com objetivo exploratório e abordagem qualitativa, utilizando-se do método hipotético-dedutivo. Por fim, conclui pela possibilidade de controle judicial do orçamento público como instrumento de efetividade da decisão que determina ao Estado a prestação adequada do direito fundamental à educação, garantindo-se a satisfação da dignidade da pessoa humana.
\end{abstract}

PALAVRAS-CHAVE: direito à educação; políticas públicas; orçamento público; controle judicial.

ABSTRACT: This work aims to demonstrate the legitimacy of judicial intervention in public policies related to the right to education, contrasting the argument of violation of the Principle of Separation of Powers, administrative discretion and the reserve of the possible. It addresses the right to education as a fundamental right, as well as the need to provide for educational public policies in the budget documents. It deals with the judicialization of public policy and the

${ }^{1}$ Doutor em Direito pela ITE de Bauru, SP. Mestre em Direito pela UENP. Professor da graduação, Mestrado e Doutorado em Direito da Universidade Estadual do Norte do Paraná (UENP). Advogado.

${ }^{2}$ Mestrando em Ciência Jurídica pela Universidade Estadual do Norte do Paraná (UENP). Especialista em Direito Público pela UNIAMÉRICA, PR. Graduado em Direito pela Universidade Estadual de Maringá (UEM). Advogado Público. 
possibility of controlling the public budget. It uses, as theoretical foundation, analysis of normative texts, doctrines and understandings signed by the Brazilian Courts. It employs a technical bibliographic research procedure, with an exploratory objective and a qualitative approach, using the hypotheticaldeductive method. Finally, it concludes for the possibility of judicial control of the public budget as an instrument for the effectiveness of the decision that determines the State to adequately provide the fundamental right to education, guaranteeing the satisfaction of the dignity of the human person.

KEYWORDS: right to education; public policy; public budget; judicial control.

\section{INTRODUÇÃO}

A Constituição Federal de 1988 consagra um Estado Democrático de Direito que tem, como finalidade, promover a justiça social por intermédio da efetivação de direitos fundamentais sociais, dentre os quais se destaca o direito à educação. Porém, existe uma realidade marcada por desafios no que diz respeito à efetivação dos direitos fundamentais sociais, posto que os Poderes Executivos e Legislativos, responsáveis pela elaboração do orçamento público, muitas vezes realizam interesses pessoais ou político-partidário, omitindo-se na formulação de políticas públicas ligadas à educação.

Diante deste descompasso com a ordem constitucional democrática, havendo falha na prestação estatal para com a realização efetiva do direito à educação, é possível buscar a atuação do Poder Judiciário que, após provocado, pode intervir nas políticas públicas, inclusive controlando o orçamento público, para garantir que os direitos fundamentais sejam concretizados de maneira adequada à satisfação da dignidade da pessoa humana.

Para tanto, inicialmente demonstra-se que o direito à educação é classificado como um direito fundamental. Em seguida, faz-se uma breve explicação sobre o orçamento público no Brasil, que funciona como instrumento definidor de políticas públicas. Posteriormente, aborda-se a judicialização das políticas públicas e a possibilidade de realização do controle pelo Poder Judiciário. Por fim, trabalha-se o controle judicial do orçamento público como instrumento de efetivação de políticas públicas na área da educação.

Portanto, será possível compreender a legitimidade da intervenção judicial no âmbito das políticas públicas, podendo controlar, inclusive, o orçamento público, sem que essa atuação viole o Princípio da Separação dos Poderes, a discricionariedade administrativa e a Teoria da Reserva do Possível. Sendo assim, esse controle judicial visa apenas a proteção da Constituição Federal de 1988 para garantir a efetividade dos direitos fundamentais sociais, resguardando a dignidade da pessoa humana. 


\section{O DIREITO À EDUCAÇÃO COMO DIREITO FUNDAMENTAL}

No Brasil, considerado um Estado democrático de direito que busca a concretização da justiça social, o tema "direitos fundamentais" ganha destaque no cenário político, jurídico e econômico porque são imprescindíveis à plena satisfação da dignidade da pessoa humana, estando constantemente nas pautas e discussões envolvendo a formulação, implementação e execução de políticas públicas.

Os direitos fundamentais podem ser compreendidos como normas positivadas na Constituição de determinado Estado e que garantem aos seus cidadãos, independentemente de classe ou nível econômico e social, as condições mínimas necessárias para uma vida digna. Por isso, "os direitos fundamentais constituem - ainda que com intensidade variável - explicitações da dignidade da pessoa humana". (SARLET, 2011, p. 101).

Para melhor compreensão sobre o conceito de direitos fundamentais, indispensável as lições de George Marmelstein (2014, p. 17-18), que assim escreve:

Os direitos fundamentais são normas jurídicas, intimamente ligadas à ideia de dignidade da pessoa humana e de limitação do poder, positivadas no plano constitucional de determinado Estado Democrático de Direito, que, por sua importância axiológica, fundamentam e legitimam todo o ordenamento jurídico.

Há cinco elementos básicos neste conceito: norma jurídica, dignidade da pessoa humana, limitação de poder, Constituição e democracia. Esses cinco elementos conjugados fornecem o conceito de direitos fundamentais. Se determinada norma jurídica tiver ligação com o princípio da dignidade da pessoa humana ou com a limitação do poder e for reconhecida pela Constituição de um Estado Democrático de Direito como merecedora de uma proteção especial, é bastante provável que se esteja diante de um direito fundamental.

Falar que os direitos fundamentais são normas constitucionais significa, por exemplo, aceitar a sua supremacia formal e material, uma das características mais importantes desses direitos (princípio da supremacia dos direitos fundamentais), bem como realça a sua força normativa, elemento essencial para se permitir a máxima efetivação desses direitos (dimensão subjetiva e princípio da máxima efetividade), [...].

No Brasil, os direitos fundamentais são considerados normas constitucionais de aplicação imediata (art. 5o, §1ํㅡ, da CF/88), positivados no Título II (dos direitos e garantias fundamentais) da Constituição Federal de 1988, e tendo recebido uma divisão em espécies a fim de conferir-lhes uma didática classificação, a saber: 
direitos individuais e coletivos (art. $5^{\circ}$ ); direitos sociais (arts. 6을 193 e seguintes); direitos de nacionalidade (art. 12); e direitos políticos (arts. 14 a 17).

Diante do rol supracitado, o art. 6을 da CF/88 elenca uma diversidade de direitos sociais, dentre os quais se destaca o direito à educação. Logo, estando previsto no texto constitucional, no título referente aos direitos fundamentais, não resta dúvida que o direito à educação é um direito fundamental e, ainda, por estar inserido no rol de direitos sociais, pode ser adjetivado como um direito fundamental social.

De forma mais detalhada, o direito fundamental social à educação encontra amparo nos arts. 205 a 214 da CF/88, tendo sido eleito pelo constituinte originário como um direito de todos e dever do Estado e da família, devendo ser promovido e incentivado com a colaboração da sociedade, no intuito de que a pessoa alcance seu pleno desenvolvimento e preparo para o exercício da cidadania, além da qualificação para o trabalho (art. 205). Já o $§ 1^{\circ}$ do art. 208 da Carta Magna conferiu ao direito à educação o status de direito público subjetivo, o que lhe garante poder ser exigido contra o Estado nos casos de omissão ou ineficiência em sua prestação.

Também é oportuno lembrar que o art. $1^{\circ}$, da CF/88 elegeu, dentre outros, a cidadania (inciso I), a dignidade da pessoa humana (inciso II) e valores sociais do trabalho e da livre iniciativa (inciso III) como fundamentos da República Federativa do Brasil.

Percebe-se que a Constituição Federal de 1988 dá especial atenção para a educação, na medida em que se trata de "importante ferramenta de emancipação do ser humano" (COELHO; REMÉDIO, 2016, p. 82), já que referido direito é a base para a satisfação dos fundamentos da República Federativa do Brasil, uma vez que proporciona a transformação pessoal do indivíduo e, também, do meio em que está inserido, funcionando como instrumento para a construção da cidadania (já que auxilia na compreensão da realidade social, econômica e política), bem como qualifica o indivíduo para o mercado de trabalho, colaborando, assim, para difundir uma cultura de respeito à dignidade da vida humana.

Compartilhando da mesma ideia, o Ministro do Supremo Tribunal Federal (STF), Celso de Mello (1986, p. 533 in LEITE; ROLIM, 2016, p. 203), ensina que:
A educação objetiva propiciar a formação necessária ao desenvolvimento das aptidões, das potencialidades e da personalidade do educando. $\mathrm{O}$ processo educacional tem por meta: (a) qualificar o educando para o trabalho; (b) prepará-lo para o exercício consciente da cidadania. O acesso à educação é uma das formas de realização concreta do ideal democrático.

No plano internacional, o direito à educação também encontra proteção tanto no Pacto Internacional dos Direitos Econômicos, Sociais e Culturais (art. 13, §1 ${ }^{\circ}$ ), promulgado pelo Decreto nº 591, de 6 de julho de 1992, quanto na Declaração 
Universal dos Direitos Humanos (art. 26, $§ 2^{\circ}$ ), sendo compreendida como um processo formativo e de desenvolvimento da personalidade do indivíduo, auxiliando-o na compreensão e gozo de uma série de outros direitos humanos e fundamentais.

A educação, portanto, é um direito fundamental social e, como tal, deve ser pautado no valor "igualdade", exigindo do Estado uma prestação (positiva) com a finalidade de se atingir a igualdade em seu sentido material. Nessa toada, o Poder Público tem o dever de fornecer educação infantil em creche e pré-escola para as crianças de 0 (zero) até 5 (cinco) anos de idade, bem como oferecer a educação básica obrigatória e gratuita dos 4 (quatro) aos 17 (dezessete) anos de idade. Nessa divisão de obrigações para com o fornecimento do direito à educação, aos Municípios compete atuar prioritariamente na educação infantil e no ensino fundamento, enquanto os Estados e o Distrito Federal devem atuar com prioridade no ensino fundamental e médio.

Para disciplinar de forma adequada o desejo do constituinte originário quanto à defesa e promoção do direito fundamental à educação, em 20 de dezembro de 1996 foi publicada a Lei no 9.394, que estabelece as diretrizes e bases da educação nacional. Posteriormente, em 25 de junho de 2014, foi publicada a Lei $\mathrm{n}^{\mathrm{o}}$ 13.005/2014, que instituiu o Plano Nacional de Educação (PNE), com o objetivo de articular o sistema nacional de educação em regime de colaboração e definir diretrizes, objetivos, metas e estratégias de implementação para assegurar a manutenção e desenvolvimento do ensino em seus diversos níveis, etapas e modalidades.

Percebe-se, assim, que a educação é tida como um direito fundamental social que proporciona ao indivíduo a garantia de participação ativa na sociedade, colaborando com seu desenvolvimento e preparo para um melhor exercício da cidadania, além de qualifica-lo adequadamente para o mercado de trabalho (PINTO, 2018, p. 61), no intuito de que desenvolva condições de viver dignamente, posto que o conhecimento adquirido permite ao indivíduo compreender e gozar os diversos outros direitos fundamentais.

\section{O ORÇAMENTO PÚBLICO COMO INSTRUMENTO DEFINIDOR DE POLÍTICAS PÚBLICAS}

O Estado tem, como uma de suas finalidades, garantir o funcionamento dos serviços básicos e essenciais à população no ensejo de satisfazer as necessidades públicas e promover o bem de todos, buscando uma justiça social. Assim agindo, trilha-se no caminho para se alcançar os objetivos fundamentais elencados pelo art. 3ㅜㅡ, da $\mathrm{CF} / 88^{3}$. Contudo para que isso seja possível, é necessário a existência de

\footnotetext{
${ }^{3}$ Art. $3^{\mathbf{o}}$. Constituem objetivos fundamentais da República Federativa do Brasil:

I - construir uma sociedade livre, justa e solidária;

II - garantir o desenvolvimento nacional;

III - erradicar a pobreza e a marginalização e reduzir as desigualdades sociais e regionais;
} 
disponibilidade financeira, situação que leva o Estado a atuar no sentido de promover a entrada de recursos suficientes aos cofres públicos.

Mas para uma atuação adequada, evitando-se gastar mais do que se arrecada (e vice-versa), é preciso que haja uma organização e planejamento das finanças públicas, com o objetivo de equilibrar as despesas e receitas públicas. E é nesse momento que ganha destaque o orçamento público, assim entendido como um instrumento legal (elaborado pelo Poder Executivo e aprovado pelo Poder Legislativo) de planejamento e organização das finanças públicas de determinado Ente Federativo, com conteúdo político, econômico, contábil e jurídico, onde são previstas as receitas e estimadas as despesas que o governo pretende realizar em um determinado exercício financeiro. (COSTA, 2017, p. 216).

A Constituição Federal de 1988 preocupou-se em trazer (nos incisos do caput do art. 165) as três ferramentas necessárias para a adequada elaboração e execução do orçamento público, a saber: Plano Plurianual (PPA), Lei de Diretrizes Orçamentárias (LDO) e Lei Orçamentária Anual (LOA).

Nos termos do art. $165, \S 1^{\circ}$, da CF/88, o PPA tem a função de estabelecer, de forma regionalizada, as diretrizes, objetivos e metas da administração pública para as despesas de capital ${ }^{4}$ e outras delas decorrentes e para as relativas aos programas de duração continuada. Já o $\S 2^{\circ}$ do art. 165, da CF/88 dispõe que a LDO compreenderá as metas e prioridades da administração pública, estabelecerá as diretrizes de política fiscal e respectivas metas, orientará a elaboração da lei orçamentária anual, disporá sobre as alterações na legislação tributária e estabelecerá a política de aplicação das agências financeiras oficiais de fomento.

Em relação à LOA, a CF/88 não trouxe uma definição (como fez com o PPA e a LDO). Contudo, pode-se dizer que se trata de um instrumento legal com a principal atribuição de trazer a previsão de receitas e a fixação de despesas para um exercício financeiro. Nesse sentido, Harisson Leite (2016, p. 143) assim conceitua a LOA:

Consiste na lei que trata da parte da execução dos projetos previstos nas diretrizes, objetivos e metas (DOM) contidas no PPA e nas metas e prioridades (MP) antevistas na LDO. Assim, é a lei que traz no seu corpo os recursos propriamente ditos, seja na parte das receitas, prevendo-as, seja na parte das despesas, fixando-as.

IV - promover o bem de todos, sem preconceitos de origem, raça, sexo, cor, idade e quaisquer outras formas de discriminação.

4 "São despesas eventuais marcadas por uma operação financeira relativa a uma aquisição patrimonial (obras, bens móveis ou imóveis etc.) ou a uma redução da dívida pública". (LEITE, 2016, p. 264). 
Para garantir o funcionamento dos serviços básicos e essenciais à população no anseio de concretizar os direitos fundamentais, sobretudo os sociais elencados no art. $6^{\circ}$, da CF/88, garantindo assim a dignidade da pessoa humana, o Estado precisa organizar adequadamente suas finanças por intermédio das peças orçamentárias, pois, como dito acima, os direitos sociais reclamam prestações positivas por parte do Poder Público e, na maioria das vezes, esta atuação gera dispêndio de recursos públicos, razão pela qual Ricardo Lobo Torres (2008, p. 499) defende que "os direitos fundamentais têm uma relação profunda e essencial com as finanças públicas. Dependem, para a sua integridade e defesa, da saúde e do equilíbrio da atividade financeira do Estado, [...]". No mesmo sentido, Osvaldo Canela Junior (2011, p. 108) aduz que "do ponto de vista do Estado social, o orçamento não pode ser óbice à concessão dos direitos fundamentais sociais, mas seu instrumento de realização".

Dentro desta necessidade de organização e planejamento orçamentário para a realização dos direitos fundamentais, principalmente os de cunho social, surge a importância do tema "políticas públicas", que, segunda Maria Paula Dallari Bucci (2006, p. 38) podem ser compreendidas como "programas de ação governamental visando coordenar os meios à disposição do Estado e as atividades privadas, para a realização de objetivos socialmente relevantes e politicamente determinados". Logo, tem-se que as políticas públicas são ações a serem realizadas pelo Poder Público visando garantir o bem comum e melhores condições para uma vida digna (RAMACCIOTTI; SOUZA e DANTAS, 2020, p. 689).

Sabendo que as políticas públicas são ações ou programas formulados para a realização dos objetivos sociais do Estado visando o atingimento do bem comum, tem-se que as mesmas não podem violar os direitos fundamentais, mas, ao contrário, devem destinar-se à sua completa realização (FREIRE JUNIOR, 2005, p. 47). Complementando esta ideia Eduardo Cambi (2020, p. 262) entende que:

Ademais, os direitos fundamentais sociais, para serem efetivados, dependem de políticas públicas. [...]. Não basta, pois, o reconhecimento formal dos direitos fundamentais; imprescindível existir meios para concretizá-los. Os direitos fundamentais (sociais) são realizados a partir de um conjunto de atividades denominado de políticas públicas - que devem ser realizados pela Administração Pública, para que os fins previstos na Constituição sejam cumpridos.

Ora, se as políticas públicas são mecanismos de efetivação dos direitos fundamentais, e se estes devem ser considerados na atividade financeira e orçamentária do Estado, é possível concluir, por silogismo lógico, que as políticas públicas também são definidas, implementadas e executadas por intermédio do orçamento público. Nesse sentido, desde a sua origem, as políticas públicas 
precisam ser consideradas nos diplomas legais orçamentários (PPA, LDO e LOA) para que possam ser realizadas adequadamente, satisfazendo os direitos fundamentais sociais dos cidadãos, já que "as políticas públicas têm ligação direta com o Estado Democrático de Direito, [...]” (SANTIN, 2013, p. 19).

Diante da constante constitucionalização do direito, o orçamento público (sendo um conjunto de leis) também deve estar em consonância com os mandamentos constitucionais, razão pela qual a escolha dos gastos públicos por meio da formulação de políticas públicas não constitui um aval irrestrito para atuação política e o exercício da discricionariedade, visto que a Constituição Federal já estabelece uma vinculação orçamentária mínima para a efetivação do núcleo essencial dos direitos fundamentais sociais, como educação (art. 212, caput, da CF/88) e saúde (art. 198, §2º , da CF/88).

Em relação ao direito à educação, visando a manutenção e desenvolvimento do ensino durante o ano, a União deve aplicar, no mínimo, 18\% da receita dos impostos, enquanto os Estados, o Distrito Federal e os Municípios devem aplicar, no mínimo, $25 \%$ da receita resultante de impostos, compreendida a proveniente de transferências.

Feitas essas considerações, verifica-se que o orçamento público é o principal instrumento definidor de políticas públicas para a efetivação dos direitos fundamentais, principalmente os de cunho social, haja vista demandarem prestações positivas por parte do Estado que, na maioria das vezes, envolve o dispêndio de recursos públicos.

\section{JUdiCIALIZAÇÃO DE POLÍticAs PÚBlicAs E A POSSIBILIDADE DE CONTROLE}

O termo "judicialização da política" pode ser entendido como uma transferência do poder político das instâncias tradicionais (Poderes Executivo e Legislativo) para o Poder Judiciário, ou seja, alguns temas de grande relevância social, econômico e, até mesmo, moral, passaram a ter a sua instância final de decisão não mais na política, mas sim no Poder Judiciário. Tal fenômeno é consequência do modelo institucional abrangente adotado pela Constituição Federal de 1988, que transformou todos os juízes e Tribunais em intérpretes da Constituição (BARROSO, 2012, p. 24).

Como visto acima, em regra, as políticas públicas inserem-se no campo das decisões políticas, cabendo aos Poderes Executivo e Legislativo a sua formulação e previsão nas leis orçamentárias, o que possibilita concluir tratar-se de ato discricionário, que demanda juízo de conveniência e oportunidade.

Porém, como os recursos públicos são limitados, no momento de dar-lhes destinação para a realização dos programas e ações do governo, os órgãos políticos devem priorizar, sobretudo, a proteção da dignidade da pessoa humana, 
dando especial atenção à satisfação dos direitos fundamentais, sobretudo os sociais (p. ex. educação, saúde, segurança, entre outros), já que a Constituição Federal criou uma vinculação para o atendimento do núcleo essencial desses direitos. Isso significa que "as escolhas em matéria de gastos públicos não constituem um tema integralmente reservado à deliberação política; ao contrário, o ponto recebe importante incidência de normas jurídicas constitucionais" (BARCELLOS, 2005, p. 90-91).

Assim, caso os gestores públicos, no momento da elaboração das peças orçamentárias, não atendam de forma alguma (omissão) ou não atendam de forma satisfatória (ação insuficiente) os direitos fundamentais (principalmente os de cunho social) e deixem de proporcionar à população as condições mínimas para uma vida digna (mínimo existencial), é possível a intervenção do Poder Judiciário para realizar o controle das políticas públicas do governo.

Assim, não caberá ao Judiciário substituir a avaliação política da autoridade competente. Deve atuar, apenas, quando caracterizadas as hipóteses de ineficiência comprovada por critérios técnicos-científicos. Em outros termos, deve intervir quando os meios escolhidos pelo Poder Público são manifestamente ineficientes ou juridicamente inválidos para realizar os fins constitucionais, notadamente se demonstrado que as opções políticas dos governantes não realizam adequadamente a garantia do mínimo existencial.

[...], a ação ou omissão da Administração no cumprimento das previsões constitucionais relativas ao orçamento enseja, como consequência, comportamento inconstitucional a ser controlado pelo Poder Judiciário.

[...]. A reserva do governante não se traduz em liberdade absoluta. Consequentemente, os gastos públicos devem ser, prioritariamente, realizados de modo a permitir a realização dos direitos fundamentais sociais, os quais são voltados a possibilitar que as pessoas possam exercer sua liberdade jurídica obtendo condições de exercer a sua liberdade real.

Evidenciando que o dinheiro público está sendo utilizado indevidamente, frustrando a realização do mínimo existencial, o Judiciário poderá efetivar o direito fundamental violado. (CAMBI, 2020, p. 544-546).

Contudo, vários são os argumentos utilizados pelo Poder Público para tentar rechaçar a possibilidade de controle judicial das políticas públicas, a saber: violação ao Princípio da Separação dos Poderes, impossibilidade de revisão 
judicial da discricionariedade administrativa e Teoria da Reserva do Possível. Porém, conforme será demonstrado a seguir, nenhum desses argumentos são suficientes para retirar a legitimidade da atuação judicial para efetivar as políticas públicas constitucionais.

Primeiramente, não se sustenta o argumento de violação do Princípio da Separação dos Poderes, pois é preciso superarmos a noção clássica de que a fiscalização judicial das outras funções do Estado seria uma intromissão indevida nos demais Poderes, até mesmo porque essa separação de função tem como finalidade dar máxima efetividade às normas constitucionais (FREIRE JÚNIOR, 2005, p. 37). Inclusive, no julgamento da Medida Cautelar na ADPF no 45/DF, o Ministro do STF, Celso de Mello, assim entendeu:

No entanto, parece-nos cada vez mais necessária a revisão do vetusto dogma da Separação dos Poderes em relação ao controle dos gastos públicos e da prestação dos serviços básicos no Estado Social, visto que os Poderes Legislativo e Executivo no Brasil se mostraram incapazes de garantir um cumprimento racional dos respectivos preceitos constitucionais. (BRASIL, 2004)

A título de reforço argumentativo, colaciona-se as lições de Arenhart (2009, p. 9-10) advertindo que "considerar a ideia de 'separação de poderes' como imposição de rígida divisão de atribuições entre o Judiciário, o Executivo e o Legislativo é algo que não tem mais pertinência em nenhum país do mundo (aí incluído o Brasil)". E o mesmo autor continua seu raciocínio dizendo que:

É, também, óbvio, portanto, que o sistema adotado pelo Brasil não é o da "separação de poderes", mas sim o do "balanceamento dos poderes". Ou seja, o direito nacional não concebe a vedação de o judiciário controlar atividades de outros "poderes" [...]. Ao contrário, no Brasil, o Judiciário tem sim a prerrogativa de interferir na atividade do Executivo e do Legislativo, para controlar a atuação destes na sua conformidade com o Direito - aí incluídos os princípios e diretrizes constitucionais. (ARENHART, 2009, p. 9-10).

Nesse sentido, quando o Poder Judiciário controla a aplicação de recursos de uma política pública, ele não está usurpando as atribuições dos agentes políticos eleitos, nem avocando para si a competência discricionária para decidir sobre a conveniência e oportunidade aplicáveis ao caso concreto. Ao contrário, sua atuação visa apenas garantir o cumprimento das normas constitucionais definidoras de direitos fundamentais, já que estas impõem uma limitação à discricionariedade administrativa. (RUSSO; LEHFELD, 2016, p. 325). 
Em segundo lugar, também não prospera o argumento de impossibilidade de revisão judicial da discricionariedade administrativa, visto que, se por um lado, na formulação da política pública o administrador (e legislador) podem agir com conveniência e oportunidade, por outro lado devem observar os limites do ordenamento jurídico, sobretudo a satisfação dos direitos fundamentais sociais previstos na Carta Magna. Dessa forma, em um Estado Democrático de Direito, a discricionariedade administrativa deve estar vinculada às prioridades eleitas na Constituição Federal, sob pena de se transformar-se em arbitrariedades, dando ensejo à atuação judicial. (FREITAS, 2009, p. 380-381).

Sabendo que as políticas públicas demandam juízo de conveniência e oportunidade do administrador e legislador e, sabendo também que a discricionariedade administrativa está vinculada às prioridades traçadas pela Constituição Federal, é possível concluir que o Poder Judiciário pode controlar a discricionariedade administrativa quando esta desviar-se da razoabilidade e proporcionalidade, deixando de atender o núcleo essencial dos direitos fundamentais sociais.

Sobre esse tema, Carvalhaes (2019, p. 73) assevera que "o controle judicial da discricionariedade deve versar sobre as questões jurídicas, a exemplo de ações governamentais que envolvam políticas públicas, a fim de coibir eventual violação aos preceitos democráticos e aos direitos fundamentais". Assim, se as escolhas políticas violarem os direitos fundamentais, o Poder Judiciário deve atuar para fazer prevalecer a superioridade da Constituição Federal frente à decisão administrativa.

Por fim, o argumento da reserva do possível também cai por terra quando confrontado com o mínimo existencial. Conforme já mencionado neste trabalho, para que o Estado realize seus fins por intermédio de prestações positivas de caráter social aos cidadãos, deverá dispender recursos financeiros, situação que também ocorre para se implementar políticas públicas (LIBERAL, 2018, p. 97).

Ocorre que, no Brasil, em razão da pobreza e da desigualdade social, as necessidades da população são infindáveis, enquanto os recursos públicos são limitados. Dessa forma, havendo a judicialização da política pública para a implementação dos direitos fundamentais sociais, o Estado constantemente aduz a Teoria da Reserva do Possível, alegando que não dispõe de recursos financeiros suficientes para realizar o bem da vida reclamado.

Porém, a tese de insuficiência financeira não pode prevalecer quando contraposta em face da necessidade de realização do mínimo existencial, que, segundo Grinover (2010, p. 132), seria o "direito às condições mínimas de existência humana digna que exige prestações positivas por parte do Estado" (p. ex., direito à educação fundamental, direito à saúde básica, direito ao saneamento 
básico, direito à assistência social, entre outros).

Ora, se de um lado tem-se uma limitação de recursos e, se do outro lado, a Constituição Federal impõe aos gestores públicos a necessidade de efetivação dos direitos fundamentais sociais, seria correto (e prudente) que, no momento da elaboração do orçamento público, primeiro houvesse destinação de recursos para o atendimento das necessidades básicas e indispensáveis da população (mínimo existencial) e, ao final, havendo sobra de recursos, aí sim destiná-los para elementos de despesas menos importante (p. ex., publicidade, festividades de final de ano, construção de praças). Reforçando esta ideia, Cambi (2020, pp. 488489; 508) assim explica:

Uma vez que os recursos públicos são limitados, devem ser aplicados, prioritariamente, na concretização de condições mínimas de tutela da dignidade da pessoa humana (mínimo existencial). Procura-se, destarte, uma otimização nos gastos públicos, voltadas à aplicação prioritária na efetivação de direitos fundamentais sociais, sem os quais as pessoas não teriam condições mínimas de sobreviver com dignidade (maximização do mínimo existencial).

[...]. Dentro das limitações orçamentárias, o Estado deve priorizar os gastos públicos na concretização daqueles direitos que permitem gerar as condições gerais mínimas para emancipação da pessoa humana, porque esta é a premissa mais favorável à realização dos direitos fundamentais em países de modernidade tardia como o Brasil. [...].

Os direitos que compõem o mínimo existencial são tão importantes que a sua outorga não pode ficar sujeita à vontade (discricionariedade) da maioria parlamentar ou da Administração Pública. Desse modo, a ausência de previsão de despesa, nas leis orçamentárias, bem como a inexistência de políticas públicas não impede a efetivação judicial do mínimo existencial. [...].

Dentro desta ideia de impossibilidade de manipulação do orçamento para privilegiar situações pessoais ou políticas (p. ex., publicidade e festividades) em detrimento da prestação do mínimo existencial, também deve-se fazer deferência à decisão monocrática proferida pelo Min. Celso de Mello no julgamento da Medida Cautelar na ADPF n⿳0 45/DF, in verbis:

Não se mostrará lícito, no entanto, ao Poder Público, em tal hipótese - mediante indevida manipulação de sua atividade 
financeira e/ou político-administrativa - criar obstáculo artificial que revele o ilegítimo, arbitrário e censurável propósito de fraudar, de frustrar e de inviabilizar o estabelecimento e a preservação, em favor da pessoa e dos cidadãos, de condições materiais mínimas de existência.

Cumpre advertir, desse modo, que a cláusula da "reserva do possível" - ressalvada a ocorrência de justo motivo objetivamente aferível - não pode ser invocada, pelo Estado, com a finalidade de exonerar-se do cumprimento de suas obrigações constitucionais, notadamente quando, dessa conduta governamental negativa, puder resultar nulificação ou, até mesmo, aniquilação de direitos constitucionais impregnados de um sentido de essencial fundamentalidade. (BRASIL, 2004).

Também é importante colacionar o entendimento firmado pela $1^{\mathrm{a}}$ Turma do Superior Tribunal de Justiça (STJ) no julgamento do Recurso Especial no 736.524/SP, que abordou a atuação judicial para a efetivação de direitos fundamentais, assim decidindo:

EMENTA: [...]. DIREITO À CRECHE EXTENSIVO AOS MENORES DE ZERO A SEIS ANOS. NORMA CONSTITUCIONAL REPRODUZIDA NO ART. 54 DO ESTATUTO DA CRIANÇA E DO ADOLESCENTE. NORMA DEFINIDORA DE DIREITOS NÃO PROGRAMÁTICA. EXIGIBILIDADE EM JUÍZO. INTERESSE TRANSINDIVIDUAL ATINENTE ÀS CRIANÇAS SITUADAS NESSA FAIXA ETÁRIA. $[\ldots]$.

12. A determinação judicial desse dever pelo Estado, não encerra suposta ingerência do judiciário na esfera da administração. Deveras, não há discricionariedade do administrador frente aos direitos consagrados, quiçá constitucionalmente. Nesse campo a atividade é vinculada sem admissão de qualquer exegese que vise afastar a garantia pétrea. [...].

15. As meras diretrizes traçadas pelas políticas públicas não são ainda direitos senão promessas de lege ferenda, encartando-se na esfera insindicável pelo Poder Judiciário, qual a da oportunidade de sua implementação.

16. Diversa é a hipótese segundo a qual a Constituição Federal consagra um direito e a norma infraconstitucional o explicita, impondo-se ao judiciário torná-lo realidade, ainda que para isso, resulte obrigação de fazer, com repercussão na esfera orçamentária. 
17. Ressoa evidente que toda imposição jurisdicional à Fazenda Pública implica em dispêndio e atuar, sem que isso infrinja a harmonia dos poderes, porquanto no regime democrático e no estado de direito o Estado soberano submete-se à própria justiça que instituiu. Afastada, assim, a ingerência entre os poderes, o judiciário, alegado o malferimento da lei, nada mais fez do que cumpri-la ao determinar a realização prática da promessa constitucional. [...].

Verifica-se então que, em situações de escassez de recursos, o gestor público deve privilegiar ações que protejam os direitos fundamentais sociais, garantindo o mínimo existencial à população, sob pena de haver uma legítima judicialização da política pública, ocasião em que o ônus de provar a ausência de recursos recai sobre o Poder Público. Nessas situações, pode o Poder Judiciário determinar a implementação da política pública que garanta condições mínimas de dignidade e, inclusive, a ordem jurídica possibilita uma série de instrumentos para dar efetividade às decisões judiciais, a saber: aplicação de multa diária (astreinte), responsabilização criminal por desobediência, resistência ou prevaricação, responsabilização pela prática de ato de improbidade administrativa, intervenção no Ente Federativo e, até mesmo, a realização de controle do orçamento público. (LIBERAL, 2018, p. 124-247).

Sendo assim, é legítimo o controle judicial de políticas públicas, não havendo qualquer violação ao Princípio da Separação dos Poderes, à discricionariedade administrativa e à reserva do possível, pois diante de direitos fundamentais sociais que resguardem a dignidade da pessoa humana, o Poder Judiciário, assim que provocado, deve atuar para obrigar o Estado a implementar políticas públicas que garantam a realização de, pelo menos, o mínimo existencial.

\section{CONTROLE JUDICIAL DO ORÇAMENTO PÚBLICO COMO INSTRUMENTO DE EFETIVAÇÃO DE POLÍTICAS PÚBLICAS NA ÁREA DA EDUCAÇÃO}

A educação pública é um direito fundamental social e, portanto, o Estado tem a responsabilidade de aplicar corretamente os recursos públicos necessários para manter o desenvolvimento do ensino. A obrigação de gasto mínimo com a educação não se esgota na aplicação dos percentuais previstos no caput do art. 212, da $\mathrm{CF} / 88$, pois a Lei no 13.005/2014, que instituiu o Plano Nacional de Educação (PNE), trouxe, como diretrizes, dentre outras, a melhoria da qualidade da educação, a erradicação do analfabetismo, a universalização da educação básica e a garantia da equidade no ensino (CAMBI, 2020, p. 510).

Sobre a importância do direito à educação, principalmente para a formação de crianças e adolescentes, a $2^{\underline{a}}$ Turma do STJ, no julgamento do Recurso Especial no 440.502/SP, assim se manifestou: 
EMENTA: [...]. DIREITO A CRECHE E A PRÉ-ESCOLA DE CRIANÇAS ATÉ SEIS ANOS DE IDADE. ESTATUTO DA CRIANÇA E DO ADOLESCENTE. [...]. PRINCÍPIO DA INAFASTABILIDADE DO CONTROLE JURISDICIONAL. LESÃO CONSUBSTANCIADA NA OFERTA INSUFICIENTE DE VAGAS. [...].

2. Na ordem jurídica brasileira, a educação não é uma garantia qualquer que esteja em pé de igualdade com outros direitos individuais ou sociais. Ao contrário, trata-se de absoluta prioridade, nos termos do art. 227 da Constituição de 1988. A violação do direito à educação de crianças e adolescentes mostrase, em nosso sistema, tão grave e inadmissível como negar-lhes a vida e a saúde. [...].

Sabendo que uma educação de qualidade interfere na formação do indivíduo e faz crescer seu espírito de cidadania, não se pode admitir que os órgãos políticos deixem de contemplar este direito fundamental nas peças orçamentárias para, ao invés disso, privilegiar despesas com publicidade, festividades, portais turísticos, construção de praças, entre outros gastos menos importantes. Porém, caso isso ocorra, é possível o controle judicial do orçamento público para fazer valer os fins constitucionais do Estado, efetivando-se prioritariamente os direitos fundamentais.

Então, havendo judicialização e consequente controle das políticas públicas ligadas ao direito fundamental à educação, é preciso garantir eficácia à decisão judicial e, para isto, o ordenamento jurídico disponibiliza ao Poder Judiciário uma série de instrumentos suficientes para tanto, dentre os quais se destaca, neste trabalho, o controle do orçamento público.

O orçamento público é o instrumento legal pelo qual o Estado (por intermédio dos órgãos políticos) fixa os objetivos constitucionais a serem perseguidos, principalmente no que diz respeito aos direitos sociais. Assim, havendo ineficácia dos órgãos políticos quanto à realização do direito à educação (p. ex., construção de uma creche), cabe ao Poder Judiciário concretizá-lo, podendo determinar a inclusão, no orçamento, de um gasto público não previsto. Ao assim agir, o Poder Judiciário não está invadindo a competência dos demais poderes, mas apenas garantindo que o Estado cumpra sua finalidade constitucional através do orçamento. (CANELA JÚNIOR, 2011, p. 106-107).

Contudo, diante deste cenário, o Poder Judiciário deve atuar com cautela, pois há uma infinidade de direitos a serem realizados pelo Estado, e os recursos disponíveis são limitados, de forma que o gasto para atendimento da ordem judicial visando a efetivação de determinado direito pode comprometer a realização de outros direitos também importantes, causando uma desorganização das políticas públicas previamente programadas. Então, no momento de decidir, 
deve o juiz utilizar-se dos Princípios da Razoabilidade e da Proporcionalidade, procurando buscar a satisfação do direito fundamental que mais proteja a dignidade da pessoa humana e que, na medida do possível, beneficie o maior número de pessoas, atingindo assim uma justiça social. (ARENHART, 2009, p. 15).

Quando se fala em controle judicial do orçamento público para efetivação de políticas públicas, é possível encontrarmos duas modalidades, a saber: o controle preventivo e o controle concomitante. Para melhor ilustrar as modalidades de controle judicial do orçamento públicos, importantes são as lições de Gajardoni (2012, p. 91), que assim escreve:

O controle orçamentário poderá ser preventivo ou concomitante. Será preventivo quando o Judiciário atuar diretamente no plano plurianual (art. 165, § 1을 da CF) ou fizer vinculação de verba programada para o orçamento do exercício seguinte (art. 165, § 5o da $\mathrm{CF}$ ), ordenando, portanto, que se reservem valores futuros para a implementação da política pública. $O$ controle concomitante - empregado nas hipóteses de absoluta urgência se dá por desvio de despesa, isto é, por meio da realocação de recursos do próprio orçamento vigente, retirando-se verba destinada à execução de obra ou serviço de menor importância (v.g., construção de praças, recapeamento asfáltico etc.) em favor da tutela do direito fundamental.

Verifica-se, então, que o controle judicial do orçamento público ocorre de forma preventiva nas situações em que o Poder Judiciário determina ao Poder Público a efetivação da política pública, porém, diante da comprovação da ausência de recursos públicos para o cumprimento imediato da ordem judicial (reserva do possível), o juiz consigna na decisão que o Estado realize imediatamente ao menos o núcleo essencial do direito (o mínimo existencial) e que, para o(s) próximo(s) orçamento(s), seja reservado dotação orçamentária específica para o atendimento completo (ou progressivo) do direito fundamental violado. A título de exemplo, suponha-se que a pretensão inicial seja a construção de uma creche para receber as crianças daquela localidade. Porém, no processo, o Município alega e prova que não possui recursos financeiros suficientes para a construir a creche naquele momento. Nesse caso, para assegurar o núcleo essencial do direito à educação, o juiz deve determinar ao Município que forneça o direito à creche de alguma forma (p. ex., pagando uma creche particular ou fazendo um Convênio para utilizar a creche do Município vizinho) e, além disso, deve determinar que seja consignado nos orçamentos futuros dotação orçamentária para a construção da creche.

[...]: o Judiciário, em face da insuficiência de recursos e de falta de previsão orçamentária, devidamente comprovadas, determinará 
ao Poder Público que faça constar da próxima proposta orçamentária a verba necessária à implementação da política pública. E, como a lei orçamentária não é vinculante, permitindo transposição de verbas, o Judiciário ainda deverá determinar, em caso de descumprimento do orçamento, a obrigação de fazer consistente na implementação de determinada política pública (a construção de uma escola ou de um hospital, por exemplo). (GRINOVER, 2013, p. 138).

Reforçando a ideia do controle judicial preventivo do orçamento público, principalmente no que diz respeito à disposição de dotações orçamentárias em orçamentos futuros para a concretização da política pública, a $2^{\underline{a}}$ Turma do STJ, no julgamento do Recurso Especial no 493.811/SP, manifestou-se nos seguintes termos:

1. Na atualidade, o império da lei e o seu controle, a cargo do Judiciário, autoriza que se examinem, inclusive, as razões de conveniência e oportunidade do administrador.

$[\ldots]$

3. Tutela específica para que seja incluída verba no próximo orçamento, a fim de atender a propostas políticas certas e determinadas. [...]. (destacamos)

E também a 2aㅗ Turma STF, no julgamento da Questão de Ordem na Petição no 2.836/RJ, assim decidiu: “[...]. Gratuidade de atendimento em creches. Determinação judicial de construção de creches pelo Município. Despesas públicas. Necessidade de autorização orçamentária: c.f. art. 167".

Por outro lado, o controle judicial do orçamento público de forma concomitante (considerado exceção porque pode desorganizar as dotações previamente programadas) é aquele em que o Poder Judiciário, em razão da urgência que o caso requer, determina ao Estado que efetive imediatamente a política pública através do remanejamento de recursos dentro da peça orçamentária vigente. Nesses casos, os Poderes Executivo e Legislativo deverão utilizarem-se das regras de Direito Financeiro, promovendo uma reprogramação das receitas previstas e despesas fixadas, cuidando para que outros direitos fundamentais não sejam prejudicados (CANELA JUNIOR, 2011, p. 107-108).

[...]. Porém, o remanejamento dos gastos públicos, bem como a abertura de créditos adicionais, cabe aos poderes políticos (Executivo e Legislativo), não ao Judiciário, que apenas reconhece a proteção ao mínimo existencial e determina que os demais poderes pratiquem os atos orçamentários cabíveis. (CAMBI, 2020, p. 512). 
Sobre o controle judicial concomitante do orçamento público e a necessidade de que o remanejamento de dotações orçamentárias seja realizado pelos Poderes Políticos, o Tribunal Pleno do STF, no julgamento da Ação Direta de Inconstitucionalidade $\mathrm{n}^{0} 5.468 / \mathrm{DF}$, assim já decidiu:

[...]

11) A Jurisdição Constitucional, em face da tessitura aberta de conformação legislativa prevista pelo inciso I do $\S 3^{\circ}$ do art. 166 da CRFB/1988, não detém capacidade institucional automática ou pressuposta e não pode empreender, no âmbito do controle abstrato, a tarefa de coordenação entre o Plano Plurianual (PPA) e as respectivas Leis de Diretrizes Orçamentárias (LDO's) e Leis Orçamentárias Anuais (LOA's).

12) Consectariamente, diante da ausência de abusividade, deve-se declarar que a função de definir receitas e despesas do aparato estatal é uma das mais tradicionais e relevantes do Poder Legislativo, impondo-se ao Poder judiciário, no caso, uma postura de deferência institucional em relação ao debate parlamentar, sob pena de indevida e ilegítima tentativa de esvaziamento de típicas funções institucionais do Parlamento. [...].

Ocorrendo o controle concomitante para garantir a imediata efetivação do direito fundamental à educação, o Poder Judiciário pode determinar ao Poder Público, por exemplo, o deslocamento de recursos originariamente destinados a gastos menos importantes (p. ex., despesas com publicidade, com festividades, com a construção de uma praça). Nesse sentido, Eduardo Cambi (2020, p. 510-511) ensina que:

Opções orçamentárias podem ser invalidadas pelo Poder Judiciário para permitir a concretização dos direitos fundamentais sociais ou, ao menos, do mínimo existencial.

[...], o Poder Judiciário deve declarar inválidas as escolhas orçamentárias ineficientes, que priorizam despesas discricionárias em face da educação básica de qualidade. Afinal, prioridade não comporta pluralidade; a escolha deve ser apenas uma.

Assim, mediante a ponderação dos valores ou dos princípios jurídicos em confronto, o Judiciário pode determinar, com base no art. 5º, XXXV, da CF/1988 (i.e., o direito à tutela jurisdicional efetiva do qual emerge o direito ao meio executivo adequado ao caso concreto) e 536, $\S 1^{\circ}$, do CPC (i.e., cláusula geral executiva 
consagradora do direito ao meio executivo adequado), o remanejamento dos gastos públicos para tornar possível a efetivação do direito fundamental social. [...].

Sendo assim, verifica-se que é perfeitamente possível a realização do controle (prévio ou concomitante) do orçamento público pelo Poder Judiciário, sobretudo quando esta intervenção é utilizada com a finalidade de dar efetividade às políticas públicas ligadas ao direito fundamental à educação. Ao agir nesse sentido, o Poder Judiciário atua legitimamente, pois não se trata de invasão nas competências dos demais Poderes da República, mas apenas uma garantia de que o Estado cumpra a finalidade constitucional de realização dos direitos fundamentais sociais.

\section{CONCLUSÃO}

O direito à educação é o principal instrumento de transformação da sociedade, na medida em oferece ao indivíduo subsídios para a compreensão da realidade social, econômica e política, contribuindo para o desenvolvimento pessoal e para o exercício da cidadania. Devido a sua importância, o direito à educação foi alçado à categoria de direito fundamental social pelo constituinte de 1988.

Portanto, sendo a educação um direito fundamental social, sua realização exige prestações positivas por parte do Estado, demandando o dispêndio de recursos públicos. Logo, as políticas públicas concretizadoras do direito à educação devem ser consideradas de forma satisfatória no orçamento público (composto pelo PPA, LDO e LOA), já que este é o instrumento de organização e planejamento do governo.

Contudo, havendo omissão ou ineficiência por parte dos órgãos políticos na formulação de políticas públicas na área da educação, é possível a provocação do Poder Judiciário para que intervenha nas decisões políticas eivadas de inconstitucionalidade. Frise-se que este controle das políticas públicas pelo Poder Judiciário não viola o Princípio da Separação de Poderes, não desrespeita a discricionariedade administrativa e, também, não desconsidera a reserva do possível. Ao contrário, esta intervenção judicial tem como finalidade restabelecer a ordem democrática e a proteção dos direitos fundamentais.

Porém, a decisão judicial que realiza o controle da política pública e determina a efetivação do direito fundamental à educação precisa ter eficácia, razão pela qual o ordenamento jurídico disponibiliza ao Poder Judiciário uma série de instrumentos suficientes para tanto, tais como: aplicação de multa diária (astreinte), responsabilização criminal por desobediência, resistência ou prevaricação, responsabilização pela prática de ato de improbidade administrativa, intervenção no Ente Federativo e, até mesmo, a realização de controle do orçamento público.

Ressalta-se, neste trabalho, a importância do controle judicial do orçamento público, já que é por meio do orçamento que se define as políticas públicas. Assim, para a efetivação da decisão que determina a realização do direito fundamental à 
educação, o Poder Judiciário pode realizar um controle prévio (determinando a inclusão, nos orçamentos futuros, de dotação suficiente para a implementação da política pública) ou concomitante (determinando que os Poderes Executivo e Legislativo operem um realinhamento de dotações no orçamento vigente, retirando recursos de finalidade menos importantes - como publicidade, festividades, construção de praças - e destinando-os para a realização do direito à educação).

Assim, vislumbra-se que o controle judicial do orçamento público visando efetivação de políticas públicas ligadas ao direito fundamental à educação é uma atuação legítima do Poder Judiciário, visto que não se trata de invasão irrestrita nas competências dos demais Poderes da República, mas, ao contrário, de atuação garantidora ao cumprimento da finalidade constitucional de proteção dos direitos fundamentais sociais, resguardando a dignidade da pessoa humana.

\section{REFERÊNCIAS}

ARENHART, Sérgio Cruz. As ações coletivas e o controle das políticas públicas pelo Poder Judiciário. Revista Custos Legis - Revista Eletrônica do Ministério Público Federal, ano I, n. 1, 2009. Disponível em: http://www.prrj.mpf.mp.br/custoslegis/revista_2009/2009/aprovados/2009a_Tut_ Col_Arenhart\%2001.pdf. Acesso em 9 jun. 2021.

BARCELLOS, Ana Paula de. Neoconstitucionalismo, direitos fundamentais e controle das políticas públicas. Revista de Direito Administrativo. v. 240, p. 83103, abr.jun. 2005. Disponível em:

http://bibliotecadigital.fgv.br/ojs/index.php/rda/article/view/43620. Acesso em 9 jun. 2021.

BARROSO, Luís Roberto. Judicialização, ativismo judicial e legitimidade democrática. (SYN)THESIS - Cadernos do Centro de Ciências Sociais da UERJ, v. 5, n. 1, p. 23-32, 2012. Disponível em: https://www.epublicacoes.uerj.br/index.php/synthesis/article/view/7433. Acesso em 9 jun. 2021.

BRASIL. Constituição da República Federativa do Brasil de 1988. Brasília, DF. Disponível em:

http://www.planalto.gov.br/ccivil_03/constituicao/constituicao.htm. Acesso em 7 jun. 2021.

BRASIL. Decreto no 591, de 6 de julho de 1992. Brasília, DF. Disponível em: http://www.planalto.gov.br/ccivil_03/decreto/1990-1994/d0591.htm. Acesso em 7 jun. 2021.

BRASIL. Lei no 8.069, de 13 de julho de 1990. Brasília, DF. Disponível em: http://www.planalto.gov.br/ccivil_03/leis/18069.htm. Acesso em 7 jun. 2021. 
BRASIL. Lei no 9.394, de 20 de dezembro de 1996. Brasília, DF. Disponível em: http://www.planalto.gov.br/ccivil_03/leis/19394.htm. Acesso em 7 jun. 2021.

BRASIL. Lei no 13.005, de 25 de junho de 2014 Brasília, DF. Disponível em: http://www.planalto.gov.br/ccivil_03/_ato2011-2014/2014/lei/113005.htm. Acesso em 7 jun. 2021.

BRASIL. Superior Tribunal de Justiça. Recurso Especial no 493.811/SP. 2ª Turma. Rel.: Min. Eliana Calmon, julg. 11/11/2003, pub. DJ 15/03/2004. Disponível em: https://processo.stj.jus.br/processo/revista/documento/mediado/?componente=IT A\&sequencial $=441599 \&$ num_registro=200201696195\&data=20040315\&peticao_nu mero=-1\&formato=PDF. Acesso em 9 jun. 2021.

BRASIL. Superior Tribunal de Justiça. Recurso Especial no 736.524/SP. $1^{\text {a }}$ Turma. Rel.: Min. Luiz Fux, julg. 21/03/2006, pub. DJ 03/04/2006. Disponível em: https://processo.stj.jus.br/processo/revista/documento/mediado/?componente=IT A\&sequencial $=614845 \&$ num_registro $=200500449414 \&$ data $=20060403 \&$ peticao_nu mero=-1\&formato=PDF. Acesso em 9 jun. 2021.

BRASIL. Superior Tribunal de Justiça. Recurso Especial no 440.502/SP. $2^{2}$ Turma. Rel.: Min. Herman Benjamin, julg. 15/12/2009, pub. DJe 24/09/2010. Disponível em: https://processo.stj.jus.br/processo/revista/documento/mediado/?componente=IT A\&sequencial $=821168 \&$ num_registro $=200200699966 \&$ data $=20100924 \&$ peticao_nu mero=-1\&formato=PDF. Acesso em 9 jun. 2021.

BRASIL. Supremo Tribunal Federal. Questão de Ordem na Petição no 2.836/RJ. Rel.: Min. Carlos Velloso, julg. 11/02/2003, pub. DJ 14/03/2003. Disponível em: https://redir.stf.jus.br/paginadorpub/paginador.jsp?docTP=AC\&docID=86517. Acesso em 9 jun. 2021.

BRASIL. Supremo Tribunal Federal. Medida Cautelar na Arguição de Descumprimento de Preceito Fundamentai no 45/DF. Rel.: Min. Celso de Mello, julg. 29/04/2004, pub. DJ 04/05/2004. Disponível em: https://jurisprudencia.stf.jus.br/pages/search/despacho120879/false. Acesso em 9 jun. 2021.

BRASIL. Supremo Tribunal Federal. Ação Direta de Inconstitucionalidade $\mathbf{n}^{\mathbf{0}}$ 5.468/DF. Rel.: Min. Luiz Fux, julg. 30/06/2016, pub. DJe 02/08/2017. Disponível em:

https://redir.stf.jus.br/paginadorpub/paginador.jsp?docTP=TP\&docID=13269137. Acesso em 9 jun. 2021. 
BUCCI, Maria Paula Dallari. O conceito de política pública em direito. In: BUCCI, Maria Paula Dallari (org.). Políticas Públicas: reflexões sobre o conceito jurídico. São Paulo: Saraiva, 2006.

CAMBI, Eduardo Augusto Salomão. Neoconstitucionalismo e

Neoprocessualismo: direitos fundamentais, políticas públicas e protagonismo judiciário. 3. ed. Belo Horizonte, São Paulo: D’Plácido, 2020.

CANELA JUNIOR, Osvaldo. Controle judicial de políticas públicas. São Paulo: Saraiva, 2011.

CARVALHAES, Andréia Schneider Nunes. Decisão judicial e políticas públicas: limites, controle e medidas judiciais. São Paulo: Revista dos Tribunais, 2019.

COELHO, Rodrigo Batista; REMÉDIO, José Antonio. Efetividade do direito à educação: positivação e justiciabilidade. Revista de Direitos Humanos e Efetividade, v. 2, n. 2, p. 75-93, jul./set. 2016. Disponível em: https://indexlaw.org/index.php/revistadhe/article/view/1553. Acesso em 7 jun. 2021.

COSTA, Wallerson Pereira da. Orçamento público: a importância do orçamento participativo na gestão pública. Revista Controle, v. 15, n. 2, p. 210-234, jul./dez. 2017. Disponível em https://revistacontrole.tce.ce.gov.br/index.php/RCDA/article/view/389. Acesso em 8 jun. 2021.

FREIRE JÚNIOR, Américo Bedê. O controle judicial de políticas públicas. São Paulo: Editora Revista dos Tribunais, 2005.

FREITAS, Juarez. O controle dos atos administrativos e os princípios fundamentais. 4. ed. refund. e ampl. São Paulo: Malheiros, 2009.

GAJARDONI, Fernando da Fonseca. Direitos Difusos e Coletivos I. In: BIANCHINI, Alice; GOMES, Luiz Flávio (coord.). Coleção Saberes do Direito, v. 34. São Paulo: Saraiva, 2012.

GRINOVER, Ada Pellegrini. O controle jurisdicional de Políticas Públicas. In: GRINOVER, Ada Pellegrini; WATANABE, Kazuo (coord.). O Controle Jurisdicional de Políticas Públicas, 2. ed. Rio de Janeiro: Forense, 2013.

LEITE, Harrison. Manual de Direito Financeiro. 5. ed. rev. ampl. e atual. Salvador: Editora Juspodivm, 2016. 
LEITE, Leonardo Canez; ROLIM, Taiane da Cruz. Direito fundamental à educação: o Estado e a importância do tripé: ensino, pesquisa e extensão. In:

BIRNFELD, Carlos André; SANCHES, Samyra Haydêe Dal Farra Naspolini; MEZZAROBA, Orides (orgs.). Anais do XXV Encontro Nacional do Conpedi. Florianópolis: CONPEDI, 2016, p. 197-213. Disponível em: http://site.conpedi.org.br/publicacoes/y0ii48h0/wz8uq8sf/fdiwXMP9EWE1w165.p df. Acesso em 7 jun. 2021.

LIBERAL, José Roberto Bernardi. Intervenção jurisdicional nas políticas públicas: mecanismos processuais de controle e efetivação. Salvador: Editora Juspodivm, 2018.

MARMELSTEIN, George. Curso de Direitos Fundamentais. 5. ed. São Paulo: Atlas, 2014.

PINTO, Élida Graziane. Prioridade alocativa da educação no ciclo orçamentário e controle do cumprimento de metas e estratégias do plano nacional de educação. Revista do TCE/MG, Edição especial, p. 50-68, 2018. Disponível em: https://revista.tce.mg.gov.br/revista/index.php/TCEMG/article/download/350/388. Acesso em 7 jun. 2021.

RAMACCIOTTI, Barbara Lucchesi; SOUZA, Camila Queiroz de; DANTAS, Rodolfo Ararigboia de Souza. O princípio da proibição do retrocesso ambiental aplicado às políticas públicas ambientais. Revista Estudos Institucionais, v. 6, n. 2, p. 685-706, maio/ago. 2020. Disponível em: https://www.estudosinstitucionais.com/REI/article/view/481/519. Acesso em 8 jun. 2021.

RUSSO, Thiago; LEHFELD, Neide. Controle jurisdicional das políticas públicas que visam concretizar o direito à saúde. Argumenta Journal Law, Jacarezinho/PR, n. 23, p. 313-331, jul. 2015/jan. 2016. Disponível em: http://seer.uenp.edu.br/index.php/argumenta/article/view/628. Acesso em 9 jun. 2021.

SANTIN, Valter Foleto. Controle judicial da segurança pública: eficiência do serviço na prevenção e repressão ao crime. 2. ed. São Paulo: Verbatim, 2013.

SARLET, Ingo Wolfgang. Dignidade da pessoa humana e direitos fundamentais na Constituição Federal de 1988. 9ª ed. Porto Alegre: Livraria do Advogado, 2011.

TORRES, Ricardo Lobo. Tratado de Direito Constitucional Financeiro e Tributário: orçamento na Constituição. 3. ed. Rio de Janeiro: Renovar, 2008. 
UNICEF. Declaração Universal dos Direitos Humanos. Disponível em: https://www.unicef.org/brazil/declaracao-universal-dos-direitos-humanos. Acesso em 7 jun. 2021. 